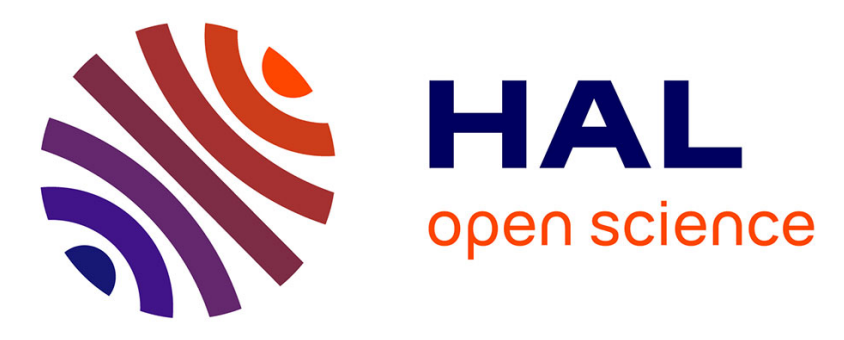

\title{
Investigation of the Adsorption of Amphipathic macroRAFT Agents onto Montmorillonite Clay
}

Rodrigo Duarte Silva, Igor Stefanichen Monteiro, Thaíssa de Camargo

Chaparro, Raíssa Silva Hardt, Reinaldo Giudici, A. Barros-Timmons, Elodie

Bourgeat-Lami, Amilton Martins dos Santos

\section{To cite this version:}

Rodrigo Duarte Silva, Igor Stefanichen Monteiro, Thaíssa de Camargo Chaparro, Raíssa Silva Hardt, Reinaldo Giudici, et al.. Investigation of the Adsorption of Amphipathic macroRAFT Agents onto Montmorillonite Clay. Langmuir, 2017, 33 (38), pp.9598 - 9608. 10.1021/acs.langmuir.7b01882 . hal-01859512

\section{HAL Id: hal-01859512 https://hal.science/hal-01859512}

Submitted on 7 Oct 2021

HAL is a multi-disciplinary open access archive for the deposit and dissemination of scientific research documents, whether they are published or not. The documents may come from teaching and research institutions in France or abroad, or from public or private research centers.
L'archive ouverte pluridisciplinaire HAL, est destinée au dépôt et à la diffusion de documents scientifiques de niveau recherche, publiés ou non, émanant des établissements d'enseignement et de recherche français ou étrangers, des laboratoires publics ou privés. 


\title{
Investigation of the adsorption of amphipathic macroRAFT agents
}

\author{
onto Montmorillonite clay
}

\author{
Rodrigo Duarte Silva, ${ }^{a}$ Igor Stefanichen Monteiro, ${ }^{a}$ Thaíssa de Camargo Chaparro, ${ }^{a, b}$ \\ Raíssa Silva Hardt, ${ }^{a}$ Reinaldo Giudici,${ }^{c}$ A. Barros-Timmons, ${ }^{d}$ Elodie Bourgeat-Lami, ${ }^{* b}$ \\ Amilton Martins dos Santos*a
}

a Engineering School of Lorena - University of São Paulo, Laboratory of Polymers, 12602-810 Lorena/SP, Brazil

${ }^{\mathrm{b}}$ Univ Lyon, Université Claude Bernard Lyon 1, CPE Lyon, CNRS, UMR 5265, Chemistry, Catalysis, Polymers and Processes (C2P2), 43 Bvd. du 11 Novembre 1918, F-69616 Villeurbanne, France

${ }^{c}$ Polytechnic School of the University of São Paulo, Department of Chemical Engineering, 05508-010 São Paulo/SP, Brazil

${ }^{\mathrm{d}}$ University of Aveiro, Department of Chemistry, CICECO - Aveiro Institute of Materials, Campus Universitário de Santiago, 3810-193 Aveiro, Portugal

*e-mail: bourgeat@lcpp.cpe.fr,amsantos@usp.br

\begin{abstract}
Recently, there has been significant interest in the use of the reversible addition-fragmentation chain-transfer (RAFT) technique to generate a variety of organic/inorganic colloidal composite particles in aqueous dispersed media using the so-called macroRAFT-assisted encapsulating emulsion polymerization (REEP) strategy. In this process, special attention should be paid to the adsorption of the macromolecular RAFT (macroRAFT) agent onto the inorganic particles as it determines the final particle morphology and can also influence latex stability. In this work, different amphipathic macroRAFT agents were synthesized by RAFT and their adsorption onto commercial Montmorillonite clay Cloisite ${ }^{\circledR} \mathrm{Na}^{+}$(MMT) was studied by means of adsorption
\end{abstract}


isotherms. Three types of macroRAFT agents were considered: a non-ionic one based on poly(ethylene glycol) methyl ether acrylate (PEGA) and $n$-butyl acrylate (BA), anionic ones, including a block copolymer and random copolymers, based on acrylic acid (AA), BA and PEGA, and cationic ones based on 2-(dimethylamino)ethyl methacrylate (DMAEMA), BA and PEGA. Six adsorption isotherm models (Langmuir, Freundlich, Tempkin, Redlich-Peterson, Sips and Brunauer-Emmett-Teller) were adjusted to the experimental isotherms. The non-ionic macroRAFT agent formed a monolayer on the clay surface with a maximum adsorption capacity of $400 \mathrm{mg} \mathrm{g}^{-1}$ at $\mathrm{pH} \mathrm{8,} \mathrm{as} \mathrm{determined} \mathrm{from} \mathrm{the} \mathrm{Sips} \mathrm{adsorption} \mathrm{model.} \mathrm{Adsorption} \mathrm{of} \mathrm{the} \mathrm{AA-}$ based macroRAFT agents onto MMT was moderate at alkaline $\mathrm{pH}$ due to electrostatic repulsions, but increased with decreasing $\mathrm{pH}$. The DMAEMA-based macroRAFT agents displayed a much stronger interaction with the oppositely charged MMT surface at acidic $\mathrm{pH}$ due to electrostatic interactions and the concentration of adsorbed macroRAFT agent reached values as high as $800 \mathrm{mg} \mathrm{g}^{-1}$. The BET model fitted the experimental data relatively well indicating multilayer adsorption promoted by the presence of the hydrophobic BA units. In addition, the cationic macroRAFT agents afforded stable MMT/macroRAFT agent complexes as evaluated by dynamic light scattering and zeta potential analyses. 


\section{INTRODUCTION}

The adsorption of polymers from solutions on solid surfaces is involved in numerous important technological applications such as the dispersion of particles in water, flocculation processes, structuring of surfaces, control of surface wettability or the introduction of surface functionalities. ${ }^{1}$ Among the numerous applications, the functionalization of inorganic nanoparticles by polymers for their efficient incorporation into polymer matrixes to prepare nanocomposite materials with superior mechanical, optical, electronic and thermal properties has received increasing attention. ${ }^{2}$ This task is particularly critical for in situ preparation of waterborne organic/inorganic hybrid latexes by emulsion polymerization, which generally relies on the polymerization of hydrophobic monomers in the presence of pre-formed inorganic nanoparticles, as colloidal stability must be maintained throughout the process. ${ }^{3,4}$ In this particular case, interaction of the growing polymer chains with the inorganic nanoparticles is usually promoted by the use of molecular coupling agents, initiator molecules or functional (macro)monomers capable of interacting with the inorganic surface. However, these approaches require the use of surfactant to stabilize the final latex particles, and it is generally admitted that the presence of free surfactant in the latex may adversely affect film formation and the properties of the final material.

A few years ago, an innovative approach involving emulsion polymerization and the reversible addition-fragmentation chain transfer (RAFT) technique was developed by Nguyen et al. for the polymer encapsulation of pigment particles in the absence of molecular surfactant. ${ }^{5}$ This strategy, coined macroRAFT-assisted encapsulating emulsion polymerization (REEP), relies on the use of water-soluble amphipathic RAFT copolymers (hereafter referred to as macroRAFT 
agents) that are capable of physically adsorbing on the surface of the inorganic nanoparticles, and stabilize them in aqueous medium. The adsorbed macroRAFT agent is then chain extended during the emulsion polymerization of hydrophobic monomers giving rise to the formation of a polymer layer around the nanoparticles as the chains grow from their surface. Since then, the method has been successfully extended to the encapsulation of various inorganic particles including gibbsite platelets, ${ }^{6}$ cerium oxide, ${ }^{7}$ colloidal silica, ${ }^{8}$ iron oxide,,${ }^{9} 10$ carbon nanotubes, ${ }^{11}$ graphene oxide sheets, ${ }^{12}$ gold nanoparticles ${ }^{13}$ and layered double hydroxides (LDHs). ${ }^{14}$ The adsorption of the macroRAFT agents on the nanoparticle surface was shown to be a key step for successful encapsulation as other morphologies than core-shell may result depending on the mechanism of adsorption. ${ }^{15,16}$

Among the nanoparticles that can be used for the preparation of hybrid latexes, clay minerals are particularly interesting as they are abundant, commercially available, inexpensive and environmentally friendly. The encapsulation of Montmorillonite (MMT) clay by REEP using cationic RAFT random copolymers has also been claimed. ${ }^{17}$ However, only a few details about the process were revealed and little attention was paid to macroRAFT agent adsorption although this is crucial for designing colloidally stable hybrid particles with controlled morphologies. Due to the characteristic charge heterogeneity of clay minerals, they can selectively interact with anionic, cationic as well as non-ionic organic species yielding hybrid materials with remarkable properties. ${ }^{18,19,20,21}$ These hybrid materials can find applications not only in the preparation of nanocomposites, but also in agriculture, in the removal of contaminants from water and in the biomedical field. ${ }^{22}$ 
Aiming to assess the influence of the adsorption of macroRAFT agents on the encapsulation of MMT platelets by REEP, a series of amphipathic macroRAFT agents with different compositions and architectures were first synthesized using the RAFT technique. These include a non-ionic random copolymer based on poly(ethylene glycol) methyl ether acrylate (PEGA) and $n$-butyl acrylate (BA), anionic macroRAFT agents containing acrylic acid (AA), PEGA and BA units and cationic copolymers comprising 2-(dimethylamino)ethyl methacrylate (DMAEMA) (with ionizable or quaternized tertiary amine groups), PEGA and BA units. Their interaction with Montmorillonite clay Cloisite ${ }^{\circledR} \mathrm{Na}^{+}$(MMT) in aqueous medium was next evaluated by means of equilibrium adsorption isotherms and the experimental data were fitted to various models in order to obtain the characteristic adsorption parameters and provide insights into the adsorption mechanism. Additionally, the effect of the adsorption of DMAEMA-based macroRAFT agents on the dispersion properties and colloidal stability of the clay platelets was also briefly assessed.

\section{EXPERIMENTAL SECTION}

\subsection{Materials}

Water was deionized before use (Polaris Ultraviolet, Reverse Osmosis, Sppencer Scientific). The organic solvents: tetrahydrofuran (THF, 100\%, Synth), 1,4-dioxane (99\%, Vetec) and $n$-hexane (100\%, Synth) were used as received. The monomers: poly(ethylene glycol) methyl ether acrylate (PEGA, $M_{\mathrm{n}}=480 \mathrm{~g} \mathrm{~mol}^{-1}$, Aldrich) and 2-(dimethylamino)ethyl methacrylate (DMAEMA, 98\%, Aldrich) were used without further purification, whereas acrylic acid (AA, 99\%, BASF) and $n$-butyl acrylate (BA, 99\%, BASF), kindly donated by BASF, were distilled 
under reduced pressure. The initiator: 4,4'-azobis(4-cyanovaleric acid) (ACPA, 98\%, Aldrich) was used as received. The RAFT agent: 4-cyano-4-thiothiopropylsulfanyl pentanoic acid (CTPPA) was obtained by reaction of ACPA with bis(propylsulfanylthiocarbonyl) disulfide according to the literature. $.^{23} 1,3,5$-Trioxane (99\%, Aldrich) was employed as internal standard for determination of monomer conversion by proton nuclear magnetic resonance analysis $\left({ }^{1} \mathrm{H}\right.$ NMR) during the synthesis of macroRAFT agents. Deuterated chloroform $\left(\mathrm{CDCl}_{3}\right)(99.96 \%$, containing $0.03 \% \mathrm{v} / \mathrm{v}$ TMS, Aldrich), deuterated water $\left(\mathrm{D}_{2} \mathrm{O}, 99.9 \%\right.$, Aldrich) and deuterated dimethyl sulfoxide (DMSO- $\mathrm{d}_{6}, 99.96 \%$, Aldrich) were used as solvents for ${ }^{1} \mathrm{H}$ NMR spectroscopy. Methyl iodide $\left(\mathrm{CH}_{3} \mathrm{I}, 99 \%\right.$, Sigma-Aldrich) was used to quaternize the amino groups of DMAEMA-based macroRAFT agents. Tetrahydrofuran (THF, 99.9\%, HPLC grade, Aldrich) was filtered and degassed in an ultrasound bath prior to being used as solvent in size exclusion chromatography (SEC). Triethylamine (TEA, 99\%, Vetec) was used as additive in THF for SEC analysis of DMAEMA-based macroRAFT agents. The carboxyl groups of AAbased macroRAFT agents were methylated with trimethylsilyl diazomethane (2M solution in diethyl ether, Aldrich) before SEC analysis. MMT (BYK Additives \& Instruments) was dispersed in water under magnetic stirring followed by sonication in an ultrasound bath for $1 \mathrm{~h}$ and centrifuged at a centrifugal acceleration of $500 \mathrm{~g}$ for $1 \mathrm{~h}$ (Allegra ${ }^{\circledR}$ 64R centrifuge, Beckman Coulter $^{\circledR}$ ) to eliminate large aggregates, resulting in a $1.0 \mathrm{wt} \%$ solid content clear aqueous dispersion.

\subsection{Methods}

\subsubsection{Synthesis of MacroRAFT Agents}


The macroRAFT agents synthesized in this work can be categorized in three groups: anionic, non-ionic and cationic copolymers. Anionic macroRAFT agents (random and block copolymers) were designed to contain AA, BA and PEGA units. They were abbreviated according to their repeating units with the subscripts representing the theoretical multiplicity of each monomer [e.g. $\mathrm{P}\left(\mathrm{AA}_{\mathrm{i}}-c o-\mathrm{PEGA}_{\mathrm{j}}-c o-\mathrm{BA}_{\mathrm{k}}\right)-\mathrm{CTPPA} \quad$ or $\left.\quad \mathrm{PAA}_{\mathrm{i}}-b-\mathrm{P}\left(\mathrm{PEGA}_{\mathrm{j}}-c o-\mathrm{BA}_{\mathrm{k}}\right)-\mathrm{CTPPA}\right] . \quad \mathrm{A}$ non-ionic macroRAFT agent containing only PEGA and BA was also synthesized $\left[\mathrm{P}\left(\mathrm{PEGA}_{\mathrm{m}}-c o-\mathrm{BA}_{\mathrm{n}}\right)-\right.$ CTPPA]. Finally, cationic macroRAFT agents containing DMAEMA and BA, with or without PEGA units, were prepared $\left[\mathrm{P}\left(\mathrm{DMAEMA}_{\mathrm{o}}-c o-\mathrm{BA}_{\mathrm{p}}\right)-\mathrm{CTPPA}\right.$ or P(DEMAEMA $\mathrm{r}_{\mathrm{r}}-c o-\mathrm{PEGA}_{\mathrm{s}}-c o-$ $\left.\mathrm{BA}_{\mathrm{t}}\right)$-CTPPA]. The experimental conditions used in the synthesis of the macroRAFT agents are displayed in Table 1 (see Supporting Information for the detailed experimental procedure).

\subsubsection{Equilibrium Adsorption Isotherms of MacroRAFT Agents onto MMT}

Firstly, the $\mathrm{pH}$ values of the stock MMT dispersion $\left(10 \mathrm{~g} \mathrm{~L}^{-1}\right)$, stock macroRAFT agent solutions $\left(40 \mathrm{~g} \mathrm{~L}^{-1}\right)$ and deionized water were adjusted to 5 or 8 with $\mathrm{NaOH}$ or $\mathrm{HCl}$ solutions $(0.5 \mathrm{mmol} \mathrm{L}$

$\left.{ }^{1}\right)$. Then, samples of MMT dispersion with macroRAFT agent were prepared by transferring 2.5 $\mathrm{mL}$ of the stock MMT dispersion to $20 \mathrm{~mL}$ glass vials and subsequently adding different amounts of stock macroRAFT agent solution to the clay dispersion in each vial so that the macroRAFT concentration in the set of samples would range from $c a .0 .8$ to $20 \mathrm{~g} \mathrm{~L}^{-1}$. Finally, calculated amounts of water were added to the vials so that the final MMT concentration in each vial reached $5 \mathrm{~g} \mathrm{~L}^{-1}$. The resulting dispersions were magnetically stirred at $500 \mathrm{rpm}$ for $24 \mathrm{~h}$ at room temperature to reach equilibrium. Then, the samples were centrifuged at $26000 \mathrm{rpm}$ for $1 \mathrm{~h}$ $\left(\right.$ Allegra $^{\circledR} 64 \mathrm{R}$ centrifuge, Beckman Coulter ${ }^{\circledR}$ ) to completely separate the solid phase composed of macroRAFT agent-adsorbed MMT. 
Table 1. Experimental Conditions Used in the Synthesis of the MacroRAFT Agents in 1,4-Dioxane Solution at $80{ }^{\circ} \mathrm{C} .{ }^{a}$

\begin{tabular}{|c|c|c|c|c|c|c|c|}
\hline $\begin{array}{c}\text { MacroRAFT } \\
\text { agent }\end{array}$ & Targeted composition & $\begin{array}{c}\text { CTPPA } \\
\left(\mathrm{mol} \mathrm{L}^{-1}\right)\end{array}$ & $\begin{array}{c}\mathrm{ACPA} \\
\left(\mathrm{mol} \mathrm{L}^{-1}\right)\end{array}$ & $\begin{array}{c}\mathrm{AA} \\
\left(\mathrm{mol} \mathrm{L}^{-1}\right)\end{array}$ & $\begin{array}{c}\text { PEGA } \\
\left(\mathrm{mol} \mathrm{L}^{-1}\right)\end{array}$ & $\begin{array}{c}\text { BA } \\
\left(\mathrm{mol} \mathrm{L}^{-1}\right)\end{array}$ & $\begin{array}{c}\text { DMAEMA } \\
\left(\mathrm{mol} \mathrm{L}^{-1}\right)\end{array}$ \\
\hline MR1 & $\mathrm{P}\left(\mathrm{PEGA}_{7}-c o-\mathrm{BA}_{4}\right)-\mathrm{CTPPA}$ & 0.063 & 0.006 & - & 0.439 & 0.253 & - \\
\hline MR2 & $\mathrm{P}\left(\mathrm{AA}_{5}-c o-\mathrm{PEGA}_{5}-c o-\mathrm{BA}_{5}\right)-\mathrm{CTPPA}$ & 0.072 & 0.007 & 0.364 & 0.361 & 0.361 & - \\
\hline MR3 & $\mathrm{P}\left(\mathrm{AA}_{10}-c o-\mathrm{PEGA}_{10}-c o-\mathrm{BA}_{10}\right)-\mathrm{CTPPA}$ & 0.036 & 0.004 & 0.385 & 0.364 & 0.363 & - \\
\hline MR4 & $\mathrm{PAA}_{45}-b-\mathrm{P}\left(\mathrm{PEGA}_{7}-c o-\mathrm{BA}_{4}\right)-\mathrm{CTPPA}$ & $0.069^{b}$ & 0.007 & - & 0.515 & 0.298 & - \\
\hline MR6 & $\mathrm{P}\left(\mathrm{DMAEMA}_{20}-c o-\mathrm{BA}_{20}\right)-\mathrm{CTPPA}$ & 0.043 & 0.004 & - & - & 0.862 & 0.861 \\
\hline MR7 & $\mathrm{P}\left(\mathrm{DMAEMA}_{30}-c o-\mathrm{BA}_{30}\right)-\mathrm{CTPPA}$ & 0.030 & 0.003 & - & - & 0.889 & 0.891 \\
\hline MR8 & $\mathrm{P}\left(\mathrm{DMAEMA}_{20}-c o-\mathrm{PEGA}_{10}-c o-\mathrm{BA}_{25}\right)$-СТPPA & 0.023 & 0.002 & - & 0.225 & 0.567 & 0.451 \\
\hline
\end{tabular}

${ }^{a}$ Volume of 1,4 -dioxane $=60 \mathrm{~mL} .{ }^{b}$ Molar concentration of PAA-CTPPA. 
The samples containing DMAEMA-based macroRAFT agents were prepared with a different order of addition of the components even though the concentrations of the macroRAFT agent solution and MMT dispersion were the same as before. Firstly, the macroRAFT agent solution was added to the vials, which was followed by the addition of the MMT dispersion. Upon stirring, the samples were sonicated using a $750 \mathrm{~W}$ Vibra Cell ${ }^{\mathrm{TM}}$ (SONICS) sonicator with a 5 $\mathrm{mm}$ tapered micro-tip, at 30\% amplitude for $2.5 \mathrm{~min}$ for homogenization of the final dispersion and only then, the solid phase was separated by centrifugation as already described. The concentration of macroRAFT agent that remained in the supernatant (equilibrium concentration of adsorbate in liquid phase), $C_{\mathrm{e}}\left(\mathrm{g} \mathrm{L}^{-1}\right)$, was experimentally determined by UV-visible spectroscopy (Genesys ${ }^{\mathrm{TM}}$ 10UV spectrophotometer, Thermo Scientific) using a linear calibration curve of absorbance as a function of macroRAFT agent concentration after appropriate dilution in deionized water where required to maintain absorbances below 1.0. The measurements were performed using quartz cuvettes with $10 \mathrm{~mm}$ optical path at a wavelength of $310 \mathrm{~nm}$, which corresponds to the maximum absorbance of the macroRAFT agent solution in the UV-visible wavelength range. ${ }^{24}$ The amount of macroRAFT agent adsorbed on MMT (equilibrium concentration of adsorbate in solid phase), $q_{\mathrm{e}}\left(\mathrm{mg} \mathrm{g}^{-1}\right)$, was evaluated by means of the difference between the initial macroRAFT agent concentration, $C_{0}\left(\mathrm{~g} \mathrm{~L}^{-1}\right)$, and the correspondent equilibrium concentration in the liquid phase:

$$
q_{e}\left(\mathrm{mg} \mathrm{g}^{-1}\right)=\frac{\left(C_{o}-C_{e}\right) V}{m} \times 10^{3}
$$

Where $V(\mathrm{~L})$ is the volume of solution and $m(\mathrm{~g})$ is the mass of clay. The adsorption isotherms 
were constructed by plotting $q_{\mathrm{e}}$ versus $C_{\mathrm{e}}$. The solid phase recovered from some samples were analyzed by X-ray diffraction (XRD) after being dried in a vacuum oven at $35^{\circ} \mathrm{C}$ for 3 days. A Philips X'PERT diffractometer with $\mathrm{Cu} k \alpha$ radiation $(\lambda=0.15405 \mathrm{~nm})$ was used and the data were collected over a range of $1-15^{\circ}(2 \theta)$ at $0.12^{\circ} \mathrm{min}^{-1}$.

\subsubsection{Modeling of Adsorption Isotherms}

The adsorption isotherm models used to fit the experimental equilibrium data are listed in Table 2.

Table 2. Equilibrium Adsorption Isotherm Models Employed to Fit the Experimental Data.

\begin{tabular}{|c|c|c|}
\hline Model & Equation & \\
\hline Langmuir & $q_{e}=q_{\max , L} \frac{K_{L} C_{e}}{1+K_{L} C_{e}}$ & 2 \\
\hline Freundlich & $q_{e}=K_{F} C_{e}^{1 / n_{F}}$ & 3 \\
\hline Temkin & $q_{e}=\frac{R T}{b_{T}} \ln A_{T} C_{e}$ & 4 \\
\hline Sips & $q_{e}=q_{\max , S} \frac{K_{S} C_{e}^{1 / n_{S}}}{1+K_{S} C_{e}^{1 / n_{S}}}$ & 5 \\
\hline Redlich-Peterson & $q_{e}=q_{\max , R P} \frac{K_{R P} C_{e}}{1+K_{R P} C_{e}^{\beta}}$ & 6 \\
\hline BET & $q_{e}=q_{\max , B} \frac{K_{B 1} C_{e}}{\left(1-K_{B 2} C_{e}\right)\left[1-K_{B 2} C_{\epsilon}\right.}$ & 7 \\
\hline
\end{tabular}


The Langmuir isotherm ${ }^{25}$ (eq 2) was originally developed for the adsorption of gases onto solid surfaces assuming: i) monolayer adsorption, ii) a homogenous adsorbent surface, iii) equal molar surface areas of both solute and solvent, and iv) no solute-solute or solute-solvent interactions. While the last two assumptions are not reasonable for the adsorption of organic molecules (such as surfactants) from liquid solutions, it has been shown that they result in this case in deviations from the Langmuir equation that are opposite to each other. ${ }^{1}$ In eq 2, the constant $q_{\max , \mathrm{L}}\left(\mathrm{mg} \mathrm{g}^{-1}\right)$ corresponds to the maximum (monolayer) adsorption capacity of the solute on the solid and $K_{\mathrm{L}}$ $\left(\mathrm{L} \mathrm{g}^{-1}\right)$ is the Langmuir equilibrium constant. The Freundlich isotherm (eq 3) is an empirical exponential equation which can be used to describe nonlinear adsorption on heterogeneous surfaces. ${ }^{26}$ The constant $K_{\mathrm{F}}\left(\mathrm{mg} \mathrm{g}^{-1}\right)$ is a relative indicator of the adsorption capacity while $n_{\mathrm{F}}$ (dimensionless) is an indicative of the energy of adsorption $\left(n_{\mathrm{F}}>1\right)$. The Tempkin adsorption model (eq 4), unlike the Langmuir model, considers the effects of some indirect adsorbate/adsorbate interactions. In eq $4, B=R T / b_{\mathrm{T}}$ is related to the heat of adsorption and $A_{\mathrm{T}}(\mathrm{L}$ $\mathrm{g}^{-1}$ ) to the maximum binding energy. The Sips equation ${ }^{27}$ (eq 5) is a generalization of both Langmuir and Freundlich models. At low adsorbate concentration, the three parameter equation approaches Freundlich isotherm; while at high concentrations, it approaches Langmuir isotherm and predicts a monolayer adsorption capacity $\left(q_{\max , \mathrm{S}}\right)$. The Redlich-Peterson isotherm ${ }^{28}$ (eq 6 ) also features both Langmuir and Freundlich isotherms into an empirical equation. At high adsorbate concentration, it approaches the Freundlich equation while for $\beta=1$, the model reduces to the Langmuir isotherm $(0<\beta \leq 1)$. Finally, the Brunauer-Emmett-Teller (BET) adsorption isotherm is a sound theoretical model that describes multilayer adsorption which was originally developed for the adsorption of gases on solid surfaces by applying the Langmuir equation to each layer assuming that the heat of adsorption of the first layer is different from that of all succeeding layers, which is equal to the heat of condensation of the liquid adsorbate. ${ }^{26}$ This 
model predicts that there is no limitation as to the number of layers that can be formed. According to Ebadi et al., ${ }^{29}$ the correct form of the BET isotherm for liquid phase adsorption is given by eq 7 , where $q_{\max , \mathrm{B}}\left(\mathrm{mg} \mathrm{g}^{-1}\right)$ is the monolayer adsorption capacity, $K_{\mathrm{B} 1}\left(\mathrm{~L} \mathrm{~g}^{-1}\right)$ is the adsorption equilibrium constant of the first layer and $K_{\mathrm{B} 2}\left(\mathrm{~L} \mathrm{~g} \mathrm{~g}^{-1}\right)$ is the adsorption equilibrium constant of upper layers. The parameters of each model were estimated by nonlinear regression (see Supporting Information for the detailed procedure).

\subsection{Characterizations}

The individual AA, BA, PEGA or DMAEMA conversions $\left(X_{\mathrm{NMR}}\right)$ during the synthesis of the macroRAFT agents, were determined by ${ }^{1} \mathrm{H}$ NMR spectroscopy (Mercury $300 \mathrm{MHz}$, Varian). Aliquots withdrawn from the reaction medium were diluted with $\mathrm{DMSO}-\mathrm{d}_{6}$ and analyzed without any purification. Monomer conversion was calculated using the integrals of 1,3,5-trioxane protons, used as internal reference, and the vinyl protons of the monomers. The molar masses of the macroRAFT agents were determined by size exclusion chromatography (SEC) (see Supporting Information for detailed experimental procedure). The particle size (hydrodynamic average diameter, $Z_{\mathrm{av}}$ ) was measured by dynamic light scattering (DLS) (Zetasizer NanoZS, Malvern Instruments), which also gave the so-called polydispersity index (PDI), an indication of

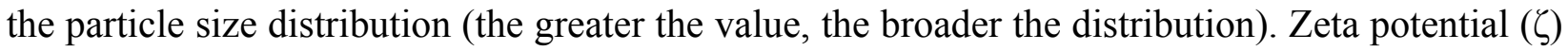
was calculated by electrophoretic mobility (Zetasizer NanoZS, Malvern Instruments). Samples for transmission electron microscopy (TEM) analyses of MMT/macroRAFT agent complexes were dropped on Formvar ${ }^{\circledR}$ coated 200 mesh copper grids and dried under air for $24 \mathrm{~h}$. The TEM images were recorded using a Philips CM120 transmission electron microscope at an accelerating voltage of $100 \mathrm{kV}$. 


\section{RESULTS AND DISCUSSION}

\subsection{Synthesis of MacroRAFT Agents}

Different types of copolymers capable of interacting with the MMT surface were synthesized in this work using the RAFT technique in order to investigate their adsorption mechanism onto MMT considering the charge heterogeneity of the MMT platelets dispersed in water. This charge heterogeneity is associated with the fact that the MMT faces have a permanent negative charge due to isomorphous substitution while positive or negative charges may arise on their edges depending on the $\mathrm{pH}$ of the medium. ${ }^{30}$ Hydroxyl groups present at the broken edges of the crystal can also contribute to adsorption. Hence, three main types of macroRAFT agent containing either a poly(ethylene oxide) side chain, anionic (AA) or cationic (DMAEMA) repeating units have been selected for this study. BA units have also been incorporated in the copolymers in order to enhance the surface wettability for the monomer mixture in the subsequent REEP process, and promote encapsulation as previously reported in the literature. ${ }^{16}$ The main characteristics of the macroRAFT agents synthesized in this work are displayed in Table 3.

Table 3. Main Characteristics of the MacroRAFT Agents Synthesized in this Work Following the Experimental Conditions Displayed in Table 1.

\begin{tabular}{|c|c|c|c|c|c|}
\hline Run & $\begin{array}{c}X_{\mathrm{NMR}}{ }^{a} \\
(\%)\end{array}$ & $\begin{array}{c}M_{\mathrm{n}, \mathrm{th}}^{b} \\
\left(\mathrm{~g} \mathrm{~mol}^{-1}\right)\end{array}$ & $\begin{array}{l}M_{\mathrm{n}, \mathrm{SEC}^{c}} \\
\left(\mathrm{~g} \mathrm{~mol}^{-1}\right)\end{array}$ & $\bigoplus^{d}$ & Structure of the macroRAFT agents \\
\hline MR1 & 68 & 2770 & 3040 & 1.14 & $\mathrm{P}\left(\mathrm{PEGA}_{4}-c o-\mathrm{BA}_{3}\right)-\mathrm{CTPPA}$ \\
\hline MR2 & 87 & 3100 & 3120 & 1.20 & $\mathrm{P}\left(\mathrm{AA}_{4}-c o-\mathrm{PEGA}_{4}-c o-\mathrm{BA}_{4}\right)-\mathrm{CTPPA}$ \\
\hline MR3 & 83 & 6230 & 5730 & 1.20 & $\mathrm{P}\left(\mathrm{AA}_{9}-c o-\mathrm{PEGA}_{9}-c o-\mathrm{BA}_{9}\right)-\mathrm{CTPPA}$ \\
\hline MR4 & 87 & 7320 & 6140 & 1.20 & $\mathrm{PAA}_{41}-b-\mathrm{P}\left(\mathrm{PEGA}_{6}-c o-\mathrm{BA}_{4}\right)-\mathrm{CTPPA}$ \\
\hline
\end{tabular}




\begin{tabular}{|c|c|c|c|c|c|}
\hline MR5 & 87 & 2310 & $1630^{e}$ & $1.42^{e}$ & $\mathrm{P}\left(\mathrm{DMAEMA}_{10}-c o-\mathrm{BA}_{4}\right)-\mathrm{CTPPA}$ \\
\hline MR6 & 77 & 4710 & $3160^{e}$ & $1.41^{e}$ & P(DMAEMA $\left.16-c o-\mathrm{BA}_{15}\right)$-CTPPA \\
\hline MR7 & 77 & 6950 & $5330^{\mathrm{e}}$ & $1.54^{e}$ & P(DMAEMA $\left.26-c o-\mathrm{BA}_{20}\right)-\mathrm{CTPPA}$ \\
\hline MR8 & 76 & 8710 & $8920^{\mathrm{e}}$ & $1.24^{e}$ & $\mathrm{P}\left(\mathrm{DMAEMA}_{17}-c o-\mathrm{PEGA}_{7}-c o-\mathrm{BA}_{19}\right)-\mathrm{CTPPA}$ \\
\hline
\end{tabular}

${ }^{a}$ Overall monomer conversion determined by $\mathrm{H}^{1} \mathrm{NMR} .{ }^{b}$ Theoretical number-average molar mass calculated taking into account $X_{\mathrm{NMR}} \cdot{ }^{c}$ Experimental molar mass determined by SEC in THF using PMMA calibration, unless otherwise indicated. ${ }^{d}$ Dispersity determined by SEC in THF using PMMA calibration, unless otherwise indicated. ${ }^{e}$ Determined by SEC in THF with TEA $\left(0.02 \mathrm{~mol} \mathrm{~L}^{-1}\right)$ using PMMA calibration.

All macroRAFTs were synthesized by RAFT polymerization in 1,4 dioxane using CTPPA as RAFT agent. The evolutions of molar mass, $M_{\mathrm{n}}$, and of molar mass distributions, $\nexists$, with conversion are shown in the Supporting Information (Figures S1-S6). As seen in Figure S1, the molar mass of P(PEGA 4 -co-BA $)$-CTPPA measured by SEC using THF increased linearly with conversion while the molar mass distribution remained low $(\nexists<1.20)$ demonstrating the good control of the copolymerization. The $M_{\mathrm{n}, \text { SEC }}$ values were slightly different from the theoretically estimated ones which may due to the fact that the PMMA standards used for the calibration of the SEC system are chemically and structurally different from the macroRAFT agent. ${ }^{31}$

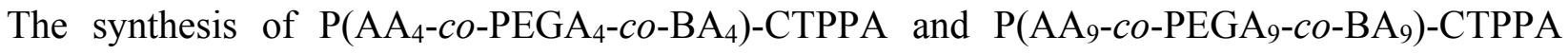
(MR2 an MR3, Table 3) also displayed features of a controlled polymerization (Figure S2). The relatively higher $D$ values measured for MR2 and MR3 at the beginning of the synthesis may be attributed to the presence of unreacted PEGA in the samples analyzed as the $\oslash$ values decreased during the synthesis and reached relatively lower values at the end. $\mathrm{PAA}_{41}-b-\mathrm{P}\left(\mathrm{PEGA}_{6}-c o-\mathrm{BA}_{4}\right)-$ CTPPA was synthesized in two steps. Firstly, well-defined PAA ${ }_{41}$-CTPPA $\left(M_{\mathrm{n}}, \mathrm{SEC}=3900 \mathrm{~g}\right.$ $\mathrm{mol}^{-1}, \oslash<1.2$ ) was synthesized (Figure S3A) and the resulting homopolymer was chainextended with BA and PEGA. The shift of the SEC traces toward higher $M_{\mathrm{n}}$ values demonstrates the successful formation of $\mathrm{PAA}_{41}-b-\mathrm{P}\left(\mathrm{PEGA}_{6}-c o-\mathrm{BA}_{4}\right)-\mathrm{CTPPA}$ diblock copolymer (Figure S3B). A series of macroRAFT agents composed of DMAEMA and BA units was also 
synthesized (MR5 to MR8 in Table 3). The characterization of these copolymers by SEC performed using pure THF as solvent and PMMA calibration revealed a linear relationship between $M_{\mathrm{n}}$, SEC and conversion which indicates that the polymerizations were well controlled (Figures S4, S5A and S6). With the exception of MR7, the dispersity of all the DMAEMA-based macroRAFT agents remained low during the synthesis and reached values typical of well-defined polymers at the end of the reaction $(\nexists<1.4)$. The experimental $M_{\mathrm{n}}$ values were lower than the theoretically estimated ones. A similar result was reported in the literature for RAFT polymerization of DMAEMA using 2-cyanoprop-2-yl dithiobenzoate as RAFT agent, and was attributed to analytical issues. ${ }^{32}$ Indeed, PDMAEMA can interact with the column packing material leading to incomplete elution. To mitigate such interactions, a small amount of TEA $\left(0.02 \mathrm{~mol} \mathrm{~L}^{-1}\right)$ was introduced in the eluent before SEC analyses. As it had been observed when SEC was performed using pure THF, the experimental $M_{\mathrm{n}}$ values increased linearly with conversion (Figures S5B and S6). In addition, the $M_{\mathrm{n}, \text { SEC }}$ values were closer to the theoretical line indicating that TEA hindered the interaction between the macroRAFT agents and the column packing material. Table 3 summarizes the $M_{\mathrm{n} \text {, SEC }}$ and $\doteq$ values of DEMAEMA-based copolymers (see Figures S4-S6 for the other values measured using pure THF).

\subsection{Adsorption Isotherms of Non-ionic and Anionic MacroRAFT Agents onto MMT}

Clay minerals exhibit different charging mechanisms in aqueous solution. Their basal planes carry a permanent negative charge due to isomorphous substitutions of the central $\mathrm{Si}$ - and $\mathrm{Al}$ atoms in the crystal lattice by lower positive valence ions whereas the edges exhibit an amphoteric behavior. Due to the charge deficiency on the basal planes, a negative potential is created at the clay surface, which is compensated by the adsorption of exchangeable cations (e.g. 
$\left.\mathrm{Na}^{+}, \mathrm{Li}^{+}, \mathrm{Ca}^{2+}\right) \cdot{ }^{33} \mathrm{MMT}$ clays intercalated with monovalent cations swell in water yielding high interlayer separations and delamination of the particles into individual silicate layers or thin assemblies constituted of a few stacked layers. The edges of MMT platelets have silanol and aluminol groups, which can protonate or deprotonate depending on the $\mathrm{pH}$ of the dispersion. Tombácz and Szekeres ${ }^{30}$ determined the point of zero charge of MMT edges ( $\mathrm{pH}_{\mathrm{PZC}}$, edge) to be 6.5 by acid-base titration. Below the $\mathrm{pH}_{\mathrm{PZC}, \text { edge, }}$ the edges acquire a net positive charge because positively charged aluminol groups exceed the negatively charged silanol groups. Above the $\mathrm{pH}_{\mathrm{PZC}, \text { edge, }}$ silanol and aluminol groups are negatively charged and the edge surface acquires a net negative charge. Recently, Pecini and Avena, ${ }^{34}$ using electrophoretic mobility measurements, reported that the $\mathrm{pH}_{\mathrm{PZC}}$, edge of MMT lies between 3.8 and 5.5. In the present study, adsorption of the non-ionic macroRAFT agent was carried out at $\mathrm{pH} 8$ while adsorption of the AA-containing macroRAFT agents was conducted at two different pHs: $\mathrm{pH} 8$ where both the edges and faces are negatively charged; and $\mathrm{pH} 5$, where the edges of the MMT platelets may be positive. ${ }^{35}$ The experimental adsorption isotherms of the non-ionic and anionic macroRAFT agents onto MMT are displayed in Figure 1.

Among the adsorption models listed in Table 2, Sips and Redlich-Peterson were the ones that gave the highest coefficients of determination $\left(R^{2}\right)$. Sips fittings are displayed in Figure 1 (solid lines) together with the experimental curves (symbols). As this model combines Langmuir and Freundlich models, each isotherm could be also reasonably fitted by one of these two-parameters models. The values of the constants of Langmuir, Freundlich and Sips models estimated by nonlinear regression are displayed in Table S1 in the Supporting Information (see Table S2 for the constants estimated for the other models). 


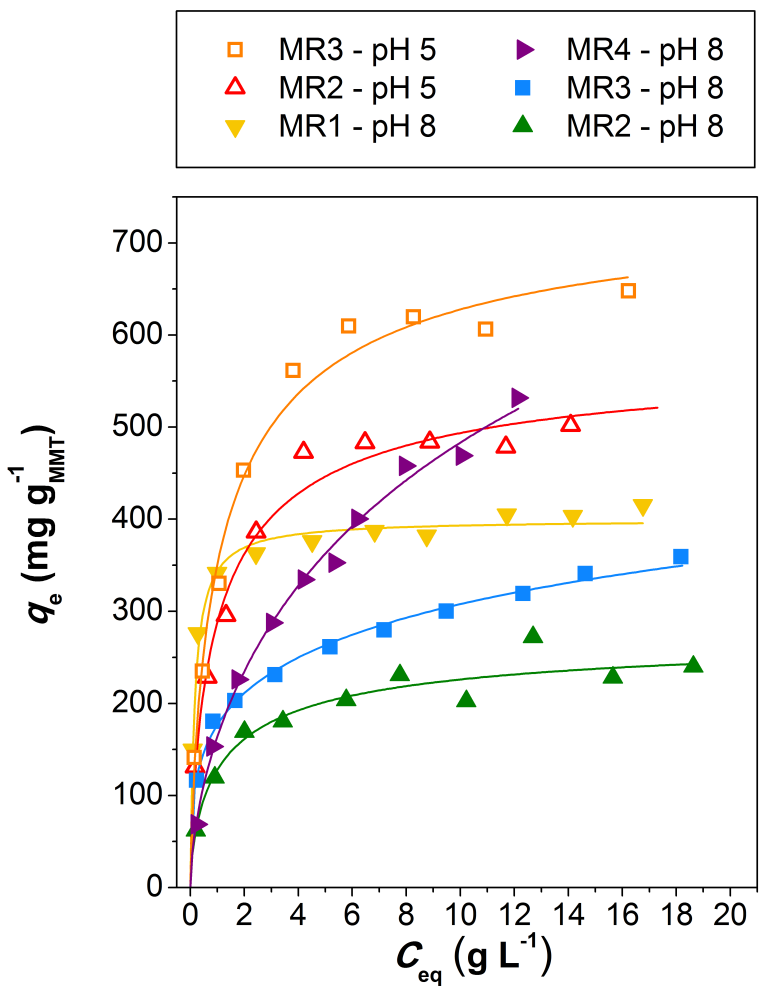

Figure 1. Experimental equilibrium adsorption isotherms of anionic and non-ionic macroRAFT agents onto MMT at pH 8 and pH $5\left(\mathrm{MMT}=5.0 \mathrm{~g} \mathrm{~L}^{-1}\right)$ at ambient temperature. MR3 - $\mathrm{P}\left(\mathrm{AA}_{9}\right.$ co-PEGA 9 -co-BA $)_{9}$-CTPPA ( $\square, \mathrm{pH} 5$ and $₫, \mathrm{pH}$ 8), MR2 - P(AA $\left.\mathrm{A}_{4}-c o-\mathrm{PEGA}_{4}-c o-\mathrm{BA}_{4}\right)-\mathrm{CTPPA}$ $(\Delta, \mathrm{pH} 5$ and $\boldsymbol{\Delta}, \mathrm{pH} 8), \mathrm{MR} 1-\mathrm{P}\left(\mathrm{PEGA}_{4}-\mathrm{co}-\mathrm{BA}_{3}\right)-\mathrm{CTPPA}(\nabla, \mathrm{pH} 8)$ and MR4 - PAA $41-b-$

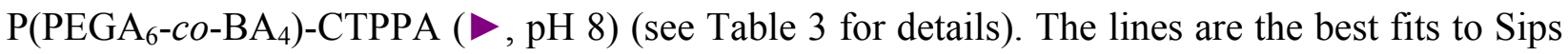
model.

The adsorption isotherm of $\mathrm{P}\left(\mathrm{PEGA}_{4}-\mathrm{co}-\mathrm{BA}_{3}\right)$-CTPPA $(\mathrm{MR} 1)$ onto MMT (Figure 1$)$ is of the $H$ type (high affinity) according to Giles classification. ${ }^{36}$ The very steep initial slope of the curve reveals a strong interaction between this non-ionic macroRAFT agent and MMT. As the macroRAFT concentration increased, the adsorption isotherm of MR1 abruptly reached a clear marked plateau, which corresponds to a maximum adsorption capacity $\left(q_{\max }\right)$ of c.a. $400 \mathrm{mg} \mathrm{g}^{-1}$ (i.e., $144 \mu \mathrm{mol} \mathrm{g}^{-1}$ ). This value is in agreement with the maximum adsorption capacity obtained by Sips fitting $\left(q_{\max , \mathrm{S}}=400 \mathrm{mg} \mathrm{g}^{-1}\right)$, demonstrating the good fit of this model to this particular 
isotherm $\left(R^{2}=0.979\right)$ (Table $\left.\mathrm{S} 1\right)$. Notice should be made that the value practically equal to 1 found for the exponential parameter of the Sips model $\left(n_{\mathrm{s}}=1.008\right)$ (Table S1) demonstrates that the MR1 isotherm follows the Langmuir model, which is also adequate to fit $H$-type curves, ${ }^{37}$ suggesting monolayer adsorption for this macroRAFT agent. The plateau of the isotherm indicates that the MMT surface becomes saturated with $\mathrm{P}\left(\mathrm{PEGA}_{4}-\mathrm{co}-\mathrm{BA}_{3}\right)-\mathrm{CTPPA}$ which must adopt a conformation on the clay surface such that the polymer in solution has little affinity for the macroRAFT-modified surface, preventing further adsorption of macroRAFT agent on the preformed layer.

Theoretically, it is expected that comb-like homopolymers adopt a flatter conformation than their linear equivalents upon adsorption on a solid surface, which results in a thinner adsorbed layer and in a larger occupied area per chain (or in a lower adsorbed mass) due to spreading of the chains on the surface, although a few experimental works have reported a higher adsorbed mass for comb-like copolymers in comparison to linear ones. ${ }^{38}$ To the best of our knowledge, there is no work in the literature reporting the adsorption behavior of non-ionic comb-like (co)polymers with PEO side chains onto MMT. On the other hand, several authors have studied the adsorption of low molar mass PEO homopolymers on MMT. The values of adsorption capacity reported for these polymers differ from each other. ${ }^{39,40,41,42}$ In general, most $q_{\max }$ values found for PEO with molar masses up to $5000 \mathrm{~g} \mathrm{~mol}^{-1}$ are not greater than $225 \mathrm{mg} \mathrm{g}^{-1}\left(56 \mu \mathrm{mol} \mathrm{g}^{-1}\right)$, which is lower than the $q_{\max }$ value of $400 \mathrm{mg} \mathrm{g}^{-1}\left(144 \mu \mathrm{mol} \mathrm{g}^{-1}\right)$ found for P(PEGA $\left.4-c o-\mathrm{BA}_{3}\right)-\mathrm{CTPPA}$. The higher adsorbed amount of $\mathrm{P}\left(\mathrm{PEGA}_{4}-\mathrm{co}-\mathrm{BA}_{3}\right)-\mathrm{CTPPA}$ is thus likely due to the presence of the hydrophobic BA units. In addition to providing an additional driving force for the adsorption process through hydrophobic interactions, the BA units may also maintain the polymer chains in a more coiled conformation preventing the PEO side chains from spreading on the clay surface, which would contribute to increase adsorption. 
As opposed to the adsorption isotherm of $\mathrm{P}\left(\mathrm{PEGA}_{4}-\mathrm{co}-\mathrm{BA}_{3}\right)-\mathrm{CTPPA}$, the adsorption isotherms of the AA-based macroRAFT agents obtained at $\mathrm{pH} 8$ (MR2, MR3 and MR4) and pH 5 (MR2 and MR3) are of the $L$-type (the adsorbed amount progressively increased with the equilibrium concentration of macroRAFT agent in the liquid phase) (Figure 1), indicating that these anionic macroRAFT agents display lower affinity for the MMT surface. Considering that the $\mathrm{p} K_{\mathrm{a}}$ of poly(acrylic acid) is $4.5,{ }^{43}$ these macroRAFT agents possibly have negatively charged AA units at $\mathrm{pH} 5$ and at $\mathrm{pH} 8$ which must have hindered their adsorption on the surface of the MMT platelets due to electrostatic repulsions. These curves do not have strict plateaus as the one corresponding to the non-ionic macroRAFT agent, which may be attributed to deviations from the Langmuir model; for instance, electrostatic repulsion between the negatively charged macroRAFT copolymers and the MMT surface. Notice should be made that the $q_{\text {max,S }}$ values

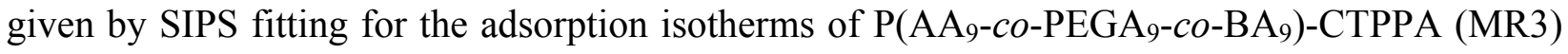
and $\mathrm{PAA}_{41}-b-\mathrm{P}\left(\mathrm{PEGA}_{6}-\mathrm{co}-\mathrm{BA}_{4}\right)-\mathrm{CTPPA}(\mathrm{MR} 4)$ at $\mathrm{pH} 8$ seems to be inaccurate (Table $\left.\mathrm{S} 1\right)$, although this model could describe relatively well the adsorption data in the range of concentrations studied. Particularly, these two isotherms could also be reasonably well fitted by the Freundlich model that does not allow for a limit in adsorption capacity, indicating cooperative adsorption.

At $\mathrm{pH} 5$, the isotherms of MR2 and MR3 displayed higher initial slopes and higher adsorption plateaus than at $\mathrm{pH} 8$, which is likely due to the lower ionization degree of the macroRAFT agents in acidic condition. In addition, electrostatic interaction between the ionized AA units and the MMT edges (which may be positively charged at $\mathrm{pH}$ 5), cannot be also completely ruled out, which would increase the affinity of these macroRAFT agents for the MMT surface and favor their adsorption. 
$\mathrm{PAA}_{41}-b-\mathrm{P}\left(\mathrm{PEGA}_{6}-\mathrm{co}-\mathrm{BA}_{4}\right)-\mathrm{CTPPA}(\mathrm{MR} 4)$ was designed so the P(PEGA-co-BA) block would adsorb on the clay surface while the PAA block would remain dangling in solution (anchor-buoy conformation) as the latter is not expected to adsorb on the negative surface of MMT platelets dispersed in alkaline medium. ${ }^{44}$ The adsorption isotherm of this macroRAFT agent determined at pH 8 displayed a contrasting shape (Figure 1). The adsorbed amount continuously increased in the range of concentrations studied and clearly did not reach a plateau. This can be tentatively attributed to interaction between the PAA block that is extended in solution in a tail-like conformation and the PEGA units of new incoming macroRAFT agent.

The adsorption of anionic polyelectrolytes on clay minerals is usually very low. The $q_{\max }$ value reported for the adsorption of PAA with $50000 \mathrm{~g} \mathrm{~mol}^{-1}$ on sodium MMT at $\mathrm{pH} 5.6$ was $6.75 \mathrm{mg}$ $\mathrm{g}^{-1}\left(0.135 \mu \mathrm{mol} \mathrm{g}{ }^{-1}\right),{ }^{45}$ while Zaman et al. ${ }^{46}$ found a maximum adsorption capacity of $1.73 \mathrm{mg} \mathrm{g}^{-1}$ (i.e., $0.51 \mu \mathrm{mol} \mathrm{g}^{-1}$ ) on kaolinite at $\mathrm{pH} 7$ for PAA with $M_{\mathrm{n}}=3400 \mathrm{~g} \mathrm{~mol}^{-1}$. Ait-Akbour et al., ${ }^{41}$ studied the adsorption of polycarboxylates containing PEO side chains (PCPs) $\left(M_{\mathrm{n}}=27000-\right.$ $51000 \mathrm{~mol} \mathrm{~g}^{-1}$ ) onto MMT at $\mathrm{pH} \mathrm{12,} \mathrm{and} \mathrm{found} q_{\max }$ values lower than typically $3.5 \mu \mathrm{mol} \mathrm{g}{ }^{-1}$. Adsorption was attributed in this last case to interaction of the PEO side chains with the inorganic surface in spite of the electrostatic repulsion. In the present study, the adsorption of all AA-based macroRAFT agents at $\mathrm{pH} 8$ exceeded $50 \mu \mathrm{mol} \mathrm{g}^{-1}$. We presume that the presence of hydrophobic BA units in their structure may have favored their adsorption due to additional hydrophobic interaction beyond the interaction between the PEO segments and the clay surface. The presence of BA units can also influence the conformation of the terpolymers resulting in more coiled chains, which would increase adsorption. At last, grouping of the AA units into a block also favored adsorption, which was tentatively attributed to the presence of dangling PAA chains stretching out in solution allowing the subsequent adsorption of new incoming macroRAFT 
agent. It is important to emphasize that all complexes showed excellent colloidal stability and that no deposit could be detected for at least 5 days.

\subsection{Adsorption Isotherms of Cationic MacroRAFT Agents onto MMT}

Two types of cationic macroRAFT agents were prepared to interact with MMT: weak polyelectrolytes based on DMAEMA, which are positively charged when the amino groups are protonated (at $\mathrm{pH} 5$, more than $95 \%$ of amino groups are supposed to be protonated), ${ }^{47}$ and strong polyelectrolytes possessing quaternized DMAEMA units (qDMAEMA), which display permanent positive charges (independent of $\mathrm{pH}$ ). Actually, very few studies have examined the interaction of DMAEMA-based (co)polymers with clay minerals. ${ }^{48,49}$ In the present work, cationic macroRAFT agents were designed not only to strongly interact with the clay surface, but also to afford stable dispersions constituted of MMT/macroRAFT agent complexes, which is crucial to obtain composite particles with controlled morphology by the REEP method.

The adsorption isotherms of DMAEMA-based macroRAFT agents onto MMT at pH 5 are displayed in Figure 2. They clearly correspond to the $H$-type, as it is generally observed for the adsorption of polycations onto clay minerals through electrostatic interactions, ${ }^{50}$ demonstrating the high affinity of the DMAEMA-based macroRAFT agents for the MMT surface. The isotherms do not display well-defined plateaus as the adsorbed amount of macroRAFT agent progressively increased in the range of concentrations studied, surpassing the stoichiometric amount necessary to exchange all the $\mathrm{Na}^{+}$cations on the clay surface, that is, $100 \%$ of the cationic exchange capacity of MMT $\left(\mathrm{CEC}=92 \mathrm{meq} / 100 \mathrm{~g}_{\mathrm{MMT}}\right)$ (see Figure S7 in Supporting Information). A similar behavior was recently reported in the literature for the adsorption of

anionic RAFT copolymers onto LDH platelets. ${ }^{14}$ Isotherms with similar shapes have also been 
reported for the adsorption of cationic polymers on MMT such as poly(diallyldimethylammonium chloride), ${ }^{51}$ poly(acrylamide-co-diallyldimethyl ammonium chloride), ${ }^{52}$ cationic starch or quaternized poly(4-vinylpyridine-co-styrene). ${ }^{53}$ The high amounts of adsorbed polycations on MMT was attributed to the conformation of the polymer chains at the solid surface: at low concentrations, the polymer adsorbs as trains while at high polymer concentrations, the adsorbed chains form loops and tails besides trains, enabling higher polymer loadings. 52,54

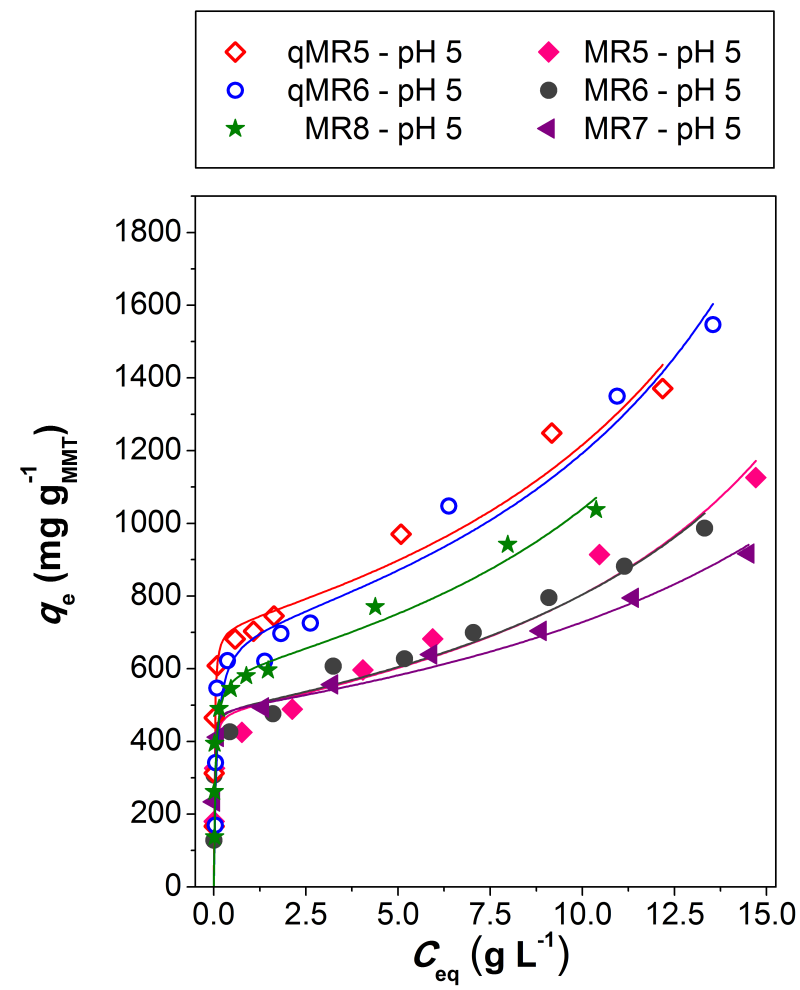

Figure 2. Experimental equilibrium adsorption isotherms of cationic macroRAFT agents onto MMT at pH $5\left(\mathrm{MMT}=5.0 \mathrm{~g} \mathrm{~L}^{-1}\right)$ at ambient temperature. qMR5 - P(qDMAEMA $\left.10-c o-\mathrm{BA}_{4}\right)$ CTPPA $(\diamond)$, qMR6 - P(qDMAEMA $16-c o-$ BA $\left._{15}\right)$-CTPPA (o), MR8 - P(DMAEMA ${ }_{17}-c o-$ PEGA $\left._{7}-c o-B_{19}\right)-C T P P A ~(\star), \quad M R 6 ~-~ P\left(D_{1 M A E M A}^{16}-c o-B_{15}\right)-C T P P A ~(\bullet), \quad M R 7 \quad-$ P(DMAEMA $\left.26-c o-\mathrm{BA}_{20}\right)$-CTPPA (४), MR5 - P(DMAEMA $\left.10-c o-\mathrm{DA}_{4}\right)-\mathrm{CTPPA}(\diamond)$. The lines are the best fits to BET model. 
The models listed in Table 2 were fitted to the experimental adsorption data and the BET model, which describes multilayer adsorption, was the one that gave the best fit among the models tested (see Tables S3 and S4 in Supporting Information for the calculated coefficients of determination). Unlike the polycations reported in the literature, the DMAEMA-based macroRAFT agents synthesized in the present work have a relatively high percentage of hydrophobic units that can enable interchain contact in the adsorbed layer and may eventually lead to multilayer formation. ${ }^{47}$ Thus, the continuous increase in the concentration of adsorbed macroRAFT agent may also be due to the formation of multilayers in addition to the conformation of the adsorbed chains mentioned above. The constants calculated by nonlinear regression for the BET model are displayed in Table S3 in Supporting Information (see Table S4 for the constants calculated for the other models). The higher values of $K_{\mathrm{B} 1}$ compared to the values of $K_{\mathrm{B} 2}$ suggest that the interaction between the macroRAFT agents and the MMT surface is stronger than possible interactions among macroRAFT agents in the upper layers.

The adsorbed mass of the quaternized macroRAFT agents P(qDMAEMA $\left.10-c o-\mathrm{BA}_{4}\right)-\mathrm{CTPPA}$ (qMR5) and $\mathrm{P}\left(\mathrm{qDMAEMA}{ }_{16}-\mathrm{co}-\mathrm{BA}_{15}\right)$-CTPPA (qMR6) were higher than that of the nonquaternized ones (MR5 to MR8). Due to the strong interaction of qMR5 and qMR6 with MMT, the adsorbed chains of these macroRAFT agents may have adopted a flat conformation on the solid surface, which should lead to a lower adsorbed amount. However, such a flat conformation may have favored the approaching of macroRAFT agent from solution, leading to the formation of subsequent layers as mentioned earlier. On the other hand, the non-quaternized macroRAFT agents may have adopted a more extended conformation on the clay surface (loops and tails) which favors adsorption but have hindered the formation of multilayers due to electrostatic repulsion between the segments of the adsorbed chains that remained extended into solution and the macroRAFT agent in solution. Zeta potential measurements indeed showed that the amount 
of quaternized macroRAFT agents needed to neutralize the MMT surface charge and impart a positive charge to the complexes was higher than the amount of their corresponding nonquaternized equivalents (MR5 and MR6) (see Figure S8 in Supporting Information). This hypothesis is also in line with the fact that the amount of $\mathrm{P}\left(\mathrm{DMAEMA}_{26}-\mathrm{co}-\mathrm{BA}_{20}\right)-\mathrm{CTPPA}$ (MR7) and P(DMAEMA $\left.{ }_{17}-c o-\mathrm{PEGA}_{7}-\mathrm{co}-\mathrm{BA}_{19}\right)$-CTPPA (MR8) needed to reverse the charge of the complexes was clearly lower than $100 \%$ of the CEC, which is attributed to the screening of the clay surface charges by a relatively high amount of segments extending into the solution (loops and tails). ${ }^{52,54}$

Among the non-quaternized macroRAFT agents, $\mathrm{P}\left(\mathrm{DMAEMA}_{17}-\mathrm{co}-\mathrm{PEGA}_{7}-\mathrm{co}-\mathrm{BA}_{19}\right)$-CTPPA (MR8) was the one that displayed the highest adsorbed mass. However, its adsorbed amount expressed in \% of CEC of MMT was the lowest (see Figure S7 in Supporting Information). MR9 has nearly the same number of DMAEMA and $\mathrm{BA}$ units as $\mathrm{P}\left(\mathrm{DMAEMA}_{16}-\mathrm{Co}-\mathrm{BA}_{15}\right)-\mathrm{CTPPA}$ (MR6) with additional pendant PEO chains, which are likely to partially adsorb on the clay surface. Therefore, MR8 may have adopted a flatter conformation on the MMT surface due to spreading of part of the PEO chains, resulting in a larger occupied area per chain, while the nonadsorbed PEO chains may have prevented further adsorption due to steric repulsion. The

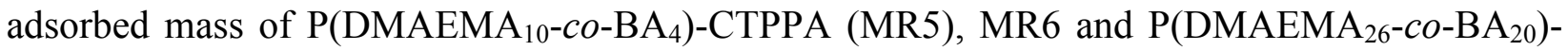
CTPPA (MR7), which all contain only DMAEMA and BA units, but have different compositions and molar masses, were similar. Among these non-quaternized macroRAFT agents, MR5 has the highest cationicity and the lowest molar mass. Based on these two characteristics, it was expected to adopt a flatter conformation on the clay surface and adsorb less than the others, which could form more loops and tails, accommodating more chains on the solid surface. ${ }^{55}$ Thus, its higher adsorbed mass can likely be attributed to the fact that the adsorbed chains of macroRAFT agent 
have adopted a less extended conformation with fewer loops or tails, promoting the subsequent adsorption of more macroRAFT agent layers by hydrophobic interactions as discussed above.

In order to get more insights into the conformation of the DMAEMA-based macroRAFT agents on the MMT surface, the MMT/P(DMAEMA $\left.{ }_{26}-\mathrm{co}-\mathrm{BA}_{20}\right)$-CTPPA complexes were characterized by XRD (Figure 3). Pristine MMT exhibits a strong reflexion at $2 \Theta=7.31^{\circ}$ corresponding to a basal spacing $\left(d_{001}\right)$ of $1.24 \mathrm{~nm}$. As the amount of adsorbed macroRAFT agent increased, the interlayer spacing increased to $2.07 \mathrm{~nm}$ whose value is of the same order of magnitude as the $\mathrm{d}_{001}$ values obtained for PDADMAC/MMT ${ }^{56}$ and chitosan/MMT ${ }^{57}$ nanocomposites. Such high interlayer distance suggests bilayer adsorption. It is important to highlight that part of the macroRAFT agent can also adsorb on the external surface of MMT as trains, loops and tails. Such polymer chains do not affect the interlayer space of MMT and are therefore not detected by XRD analysis.

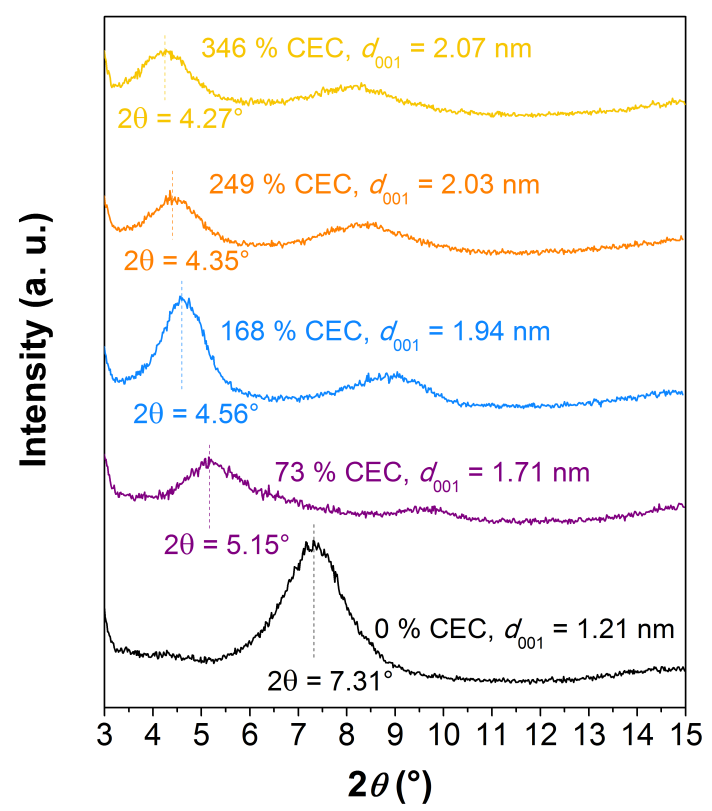

Figure 3. $\mathrm{XRD}$ patterns of $\mathrm{MMT} / \mathrm{P}\left(\mathrm{DMAEMA}_{26}-\mathrm{Co}-\mathrm{BA}_{20}\right)$-CTPPA complexes for increasing amounts of adsorbed macroRAFT agent expressed as percentage of the cation exchange capacity $(\mathrm{CEC})$ of MMT $\left(\mathrm{MMT}=5.0 \mathrm{~g} \mathrm{~L}^{-1}\right)$. 
In order to be used in applications where a high colloidal stability is needed, such as the synthesis of colloidal nanocomposites, the MMT/macroRAFT agent complexes must be stable. It is known that the stability of colloidal inorganic particles in the presence of oppositely charged polyelectrolytes strongly depends on the concentration of the polyelectrolyte. ${ }^{58}$ The dispersion is stable at low polyelectrolyte concentration but as the polyelectrolyte concentration increases, the stability decreases, until the system becomes completely unstable (near the charge neutralization point). When the polyelectrolyte concentration is further increased, charge reversal occurs and the dispersion is stabilized again. In this work, we investigated the effect of the addition of DMAEMA-based macroRAFT agents on the aggregation of MMT nanoparticles. The zeta potential of the complexes and their average hydrodynamic diameter as a function of the adsorbed amount of macroRAFT agent are displayed in Figures 4A and 4B respectively (the scale of the vertical axis in Figure 4B was interrupted at $750 \mathrm{~nm}$ so it could be read more precisely; for the graph with an enlarged scale, see Figure S8A in Supporting Information). It is worth mentioning here that although DLS assumes spherical particles, and may not be therefore fully appropriate for lamellar particles, the particle sizes determined by this technique can nevertheless give an estimation of the effective hydrodynamic diameter of an equivalent sphere, ${ }^{59}$ and allow for a useful comparison between all the samples. 

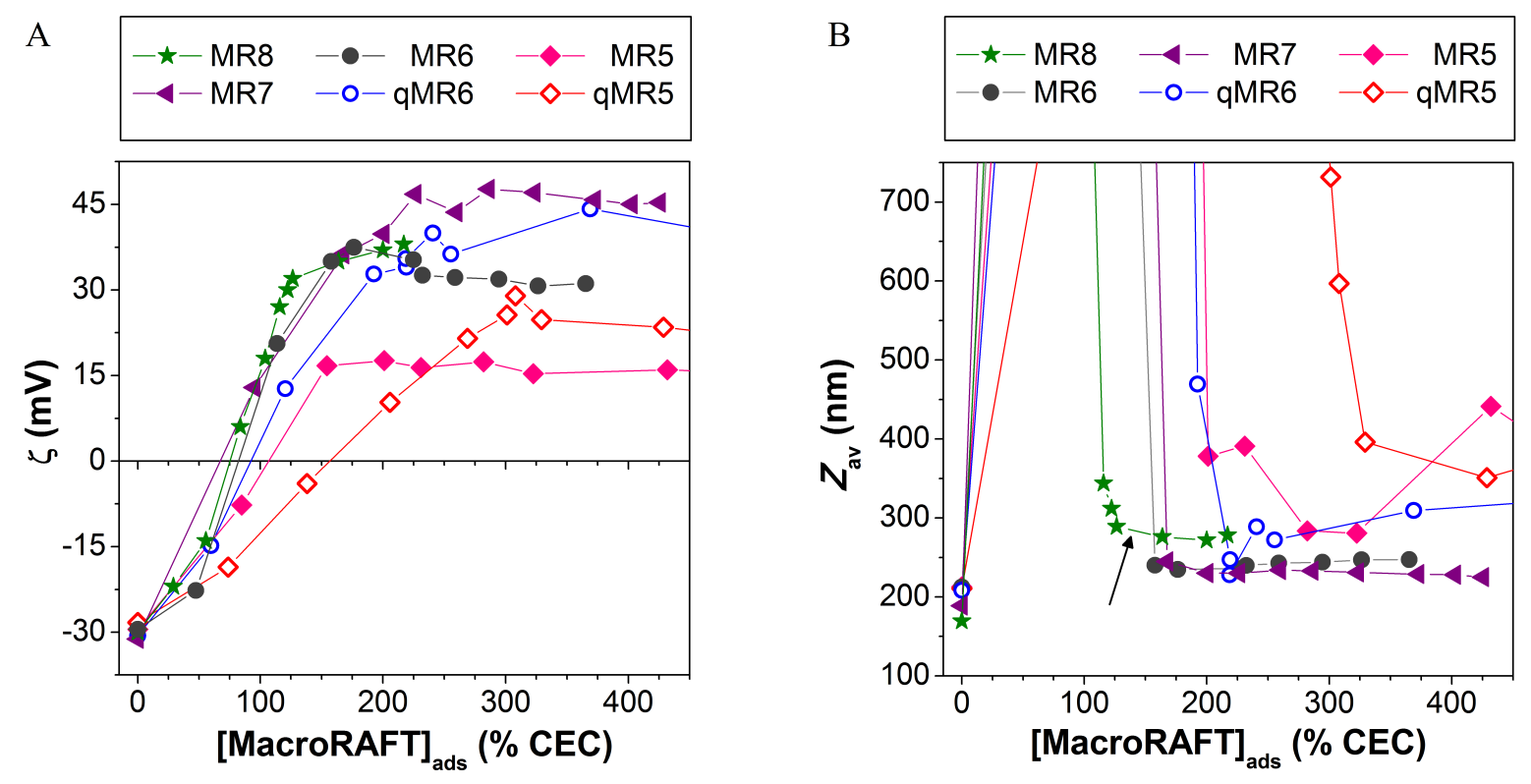

Figure 4. (A) Zeta potential (ל) and (B) particle size $\left(Z_{\mathrm{av}}\right)$ of MMT/macroRAFT agent complexes as a function of the adsorbed amount of cationic macroRAFT agent expressed in \% of CEC of MMT $\left(\mathrm{MMT}=5.0 \mathrm{~g} \mathrm{~L}^{-1}\right)$. The lines are guides for the eyes. MR8 - P(DMAEMA $17-c o-\mathrm{PEGA}_{7}$ co-BA 19$)$-CTPPA ( $\star)$, MR7 - P(DMAEMA $\left.26^{-} c o-\mathrm{BA}_{20}\right)$-CTPPA ( ४), MR6 - P(DMAEMA ${ }_{16}-c o-$ BA $\left._{15}\right)$-CTPPA (•), qMR6 - P(qDMAEMA $\left.16-c o-\mathrm{BA}_{15}\right)$-CTPPA (०), MR5 - P(DMAEMA ${ }_{10}-c o-$ $\left.\mathrm{BA}_{4}\right)-\mathrm{CTPPA}(\diamond), \mathrm{qMR} 5-\mathrm{P}\left(\mathrm{qDMAEMA} 10-\mathrm{co}-\mathrm{BA}_{4}\right)-\mathrm{CTPPA}(\diamond)$.

For low concentrations of macroRAFT agent, corresponding to adsorbed amounts lower than $50 \%$ of CEC, even though the negative charge of MMT particles was only partially neutralized by the macroRAFT agent (Figure 4A), the dispersion instantly underwent severe aggregation resulting in an increase of particle size (Figure 4B) and in broader particle size distributions as indicated by the polydispersity indexes higher than 0.3 (see Figure S8B in Supporting Information for the PDI of the complexes as a function of the adsorbed amount of macroRAFT agent). These particles could not be redispersed indicating poor stability, which was also visually noticed due the presence of macroscopic aggregates and sedimentation. For higher concentrations of macroRAFT agents resulting in adsorbed amounts higher than at least $125 \%$ of CEC, the 
complexes could be redispersed as indicated by $Z_{\mathrm{av}}$ and $P D I$ values relatively closer to those corresponding to bare MMT particles (Figure 4B and S8B). The complexes prepared with

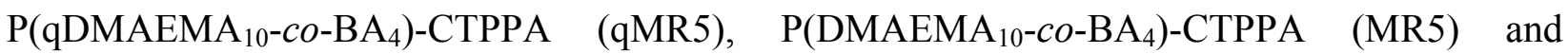
P(qDMAEMA $16-c o-\mathrm{BA}_{15}$ )-CTPPA (qMR6) displayed relatively higher $Z_{\mathrm{av}}$ and $P D I$ values indicating that these copolymers were less effective for dispersing the particles, which is likely related to the conformation of the adsorbed chains discussed above. The macroRAFT agent most effective to disperse the particles was $\mathrm{P}\left(\mathrm{DMAEMA}_{17}-\mathrm{co}-\mathrm{PEGA}_{7}-\mathrm{co}-\mathrm{BA}_{19}\right)$-CTPPA (MR8) as an adsorbed amount corresponding to $125 \%$ of CEC was sufficient to yield complexes with sizes comparable to the size of bare MMT particles which may be due to additional steric stabilization imparted by PEO chains dangling in solution. In order to verify the stability of the complexes, the dispersions were analyzed by DLS five days after the first analysis. For each macroRAFT agent, the results from both analyses are displayed in Figure S9A-9F in Supporting Information. The particle size of the complexes prepared with qMR5, MR5 and qMR6 considerably increased in comparison to the particle size of complexes prepared with MR6, MR7 and MR8 indicating loss of stability.

The MMT/P(DMAEMA $\left.{ }_{17}-c o-\mathrm{PEGA}_{7}-c o-\mathrm{BA}_{19}\right)$-CTPPA complex prepared with $6.5 \mathrm{~g} \mathrm{~L}^{-1}$ of macroRAFT agent, which corresponds to the experiment indicated by a black arrow in Erreur ! Source du renvoi introuvable., was analyzed by TEM (Figure 5).. In Figure 5B, it is possible to see objects with very low contrast that resemble individual platelets (or stacks of a few platelets) lying flat on the TEM grid. The low contrast is attributed to the very small thickness of the MMT platelets (around $1 \mathrm{~nm}$ ). This result confirms the effectiveness of this macroRAFT agent in dispersing the particles. 

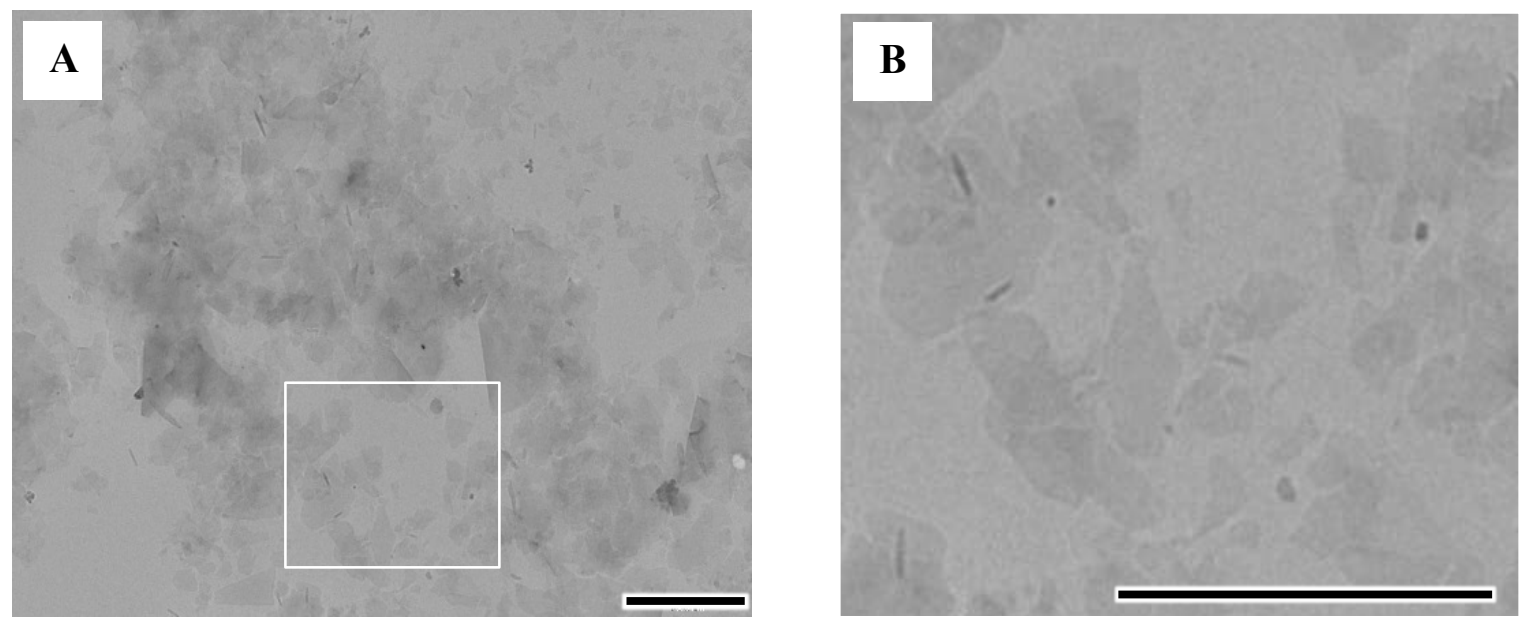

Figure 5. (A) TEM images of $\mathrm{MMT} / \mathrm{P}\left(\mathrm{DMAEMA}_{17}-c o-\mathrm{PEGA}_{7}-c o-\mathrm{BA}_{19}\right)-\mathrm{CTPPA}$ $\left([\mathrm{MMT}]=5.0 \mathrm{~g} \mathrm{~L}^{-1}\right.$; [macroRAFT agent $\left.]=6.5 \mathrm{~g} \mathrm{~L}^{-1}\right)$. (B) Zoom of insert in Figure A. Scale bars: $1 \mu \mathrm{m}$.

\section{CONCLUSIONS}

MacroRAFT agents with different structures and compositions were successfully synthesized by RAFT polymerization in solution. SEC analysis confirmed the controlled character of the polymerizations. The interaction of these copolymers with MMT clay was investigated by means of experimental adsorption isotherms that were adjusted to six theoretical adsorption models. The non-ionic macroRAFT agent: $\mathrm{P}\left(\mathrm{PEGA}_{7}-\mathrm{Co}-\mathrm{BA}_{4}\right)$-CTPPA, displayed a stronger affinity for the clay surface than the anionic ones and formed a monolayer on the MMT surface. In turn, the adsorption of AA-based macroRAFT agents was influenced by the copolymer structure and by the $\mathrm{pH}$ of the dispersion. At $\mathrm{pH} 8$, the adsorbed mass of $\mathrm{PAA}_{41}-b-\mathrm{P}\left(\mathrm{PEGA}_{6}-c o-\mathrm{BA}_{4}\right)-\mathrm{CTPPA}$ was

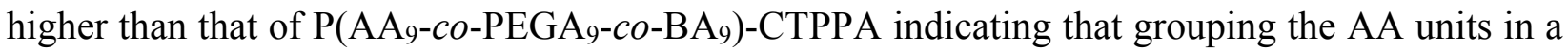
block favored adsorption. At $\mathrm{pH} 5$, the adsorption of the AA-containing random copolymers was higher than at $\mathrm{pH} 8$ as a result of the lower ionization degree and possibly also to interaction with 
the clay edges. The DMAEMA-based macroRAFT agents strongly adsorbed on the MMT surface due to electrostatic interaction between the polyelectrolyte and the negatively-charged surface. High copolymer loadings were achieved with these macroRAFT agents suggesting multilayer adsorption. The incorporation of PEO side chains in the copolymers resulted in a higher adsorbed mass although the number of adsorbed chains decreased, which is in line with the adsorption of part of the PEO pendant chains on the MMT surface in a more flat conformation. Stable complexes could be prepared with the cationic macroRAFT agents, which is a fundamental requirement for many applications as the synthesis of hybrid latexes by RAFT-mediated emulsion polymerization. In particular, the complexes prepared with $\mathrm{P}\left(\mathrm{DMAEMA}_{17}-\mathrm{co}-\mathrm{PEGA}_{7}\right.$ co-BA 19 )-CTPPA displayed remarkable colloidal stability probably due to the steric stabilization imparted by the non-adsorbed PEO chains.

\section{ASSOCIATED CONTENT}

\section{Supporting Information}

The Supporting Information is available free of charge via the Internet at http://pubs.acs.org. Experimental procedure for the synthesis of the macroRAFT agents; SEC analysis of the macroRAFT agents; estimation of model parameters; adsorption isotherms of the cationic macroRAFT agents onto MMT with adsorbed amount expressed in percentage of CEC of MMT; particle size of MMT/macroRAFT agent complexes as a function of the adsorbed amount of DMAEMA-based macroRAFT agents 5 days after preparation.

\section{AUTHOR INFORMATION}




\section{Corresponding Authors}

*E-mail: bourgeat@1ccp.cpe.fr (E.B-L.)

*E-mail: amsantos@usp.br (A.M.S.)

\section{Notes}

The authors declare no competing financial interest.

\section{ACKNOWLEDGMENTS}

This work was developed in the scope of the ENCIRCLE (Polymer-encapsulation of anisotropic inorganic particles by RAFT-mediated emulsion polymerization) project enabled by IUPAC. The authors acknowledge FAPESP (Brazil), CNRS (France) and FCT/MEC (Portugal) funding agencies for financial support.

\section{REFERENCES}

1. Holmberg, K.; Jönsson, B.; Kronberg, B.; Lindman, B., Surfactants and polymers in aqueous solution. 2nd ed.; Chichester, 2002.

2. Kango, S.; Kalia, S.; Celli, A.; Njuguna, J.; Habibi, Y.; Kumar, R., Surface modification of inorganic nanoparticles for development of organic-inorganic nanocomposites-A review. Prog. Polym. Sci. 2013, 38, 1232-1261.

3. Bourgeat-Lami, E.; Lansalot, M., Organic/Inorganic Composite Latexes: The Marriage of Emulsion Polymerization and Inorganic Chemistry. Adv. Polym. Sci. 2010, 233, 53-123.

4. Bourgeat-Lami, E.; Sheibat-Othman, N.; Dos Santos, A. M., Chapter 13 Polymer-Clay Nanocomposite Particles and Soap-free Latexes Stabilized by Clay Platelets: State of the Art 
and Recent Advances. In Polymer Nanocomposites by Emulsion and Suspension Polymerization, The Royal Society of Chemistry: 2011; pp 269-311.

5. Nguyen, D.; Zondanos, H. S.; Farrugia, J. M.; Serelis, A. K.; Such, C. H.; Hawkett, B. S., Pigment Encapsulation by Emulsion Polymerization Using Macro-RAFT Copolymers. Langmuir 2008, 24, 2140-2150.

6. Ali, S. I.; Heuts, J. P. A.; Hawkett, B. S.; van Herk, A. M., Polymer Encapsulated Gibbsite Nanoparticles: Efficient Preparation of Anisotropic Composite Latex Particles by RAFTBased Starved Feed Emulsion Polymerization. Langmuir 2009, 25, 10523-10533.

7. Zgheib, N.; Putaux, J.-L.; Thill, A.; Bourgeat-Lami, E.; D'Agosto, F.; Lansalot, M., Cerium oxide encapsulation by emulsion polymerization using hydrophilic macroRAFT agents. Polym. Chem. 2013, 4, 607-614.

8. Bourgeat-Lami, E.; França, A. J. P. G.; Chaparro, T. C.; Silva, R. D.; Dugas, P. Y.; Alves, G. M.; Santos, A. M., Synthesis of Polymer/Silica Hybrid Latexes by Surfactant-Free RAFTMediated Emulsion Polymerization. Macromolecules 2016, 49, 4431-4440.

9. Nguyen, D.; Pham, B. T. T.; Huynh, V.; Kim, B. J.; Pham, N. T. H.; Bickley, S. A.; Jones, S. K.; Serelis, A.; Davey, T.; Such, C.; Hawkett, B. S., Monodispersed polymer encapsulated superparamagnetic iron oxide nanoparticles for cell labeling. Polymer 2016, 106, 238-248.

10. Li, K.; Dugas, P.-Y.; Bourgeat-Lami, E.; Lansalot, M., Polymer-encapsulated $\gamma$-Fe2O3 nanoparticles prepared via RAFT-mediated emulsion polymerization. Polymer 2016, 106, 249-260.

11. Nguyen, D.; H., C.; Hawkett, B. S., Polymer coating of carboxylic acid functionalized multiwalled carbon nanotubes via reversible addition-fragmentation chain transfer mediated emulsion polymerization. J. Polym. Sci. Part A: Polym. Chem. 2013, 51, 250-257. 
12. Huynh, V. T.; Nguyen, D.; Such, C. H.; Hawkett, B. S., Polymer coating of graphene oxide via reversible addition-fragmentation chain transfer mediated emulsion polymerization. $J$. Polym. Sci. Part A: Polym. Chem. 2015, 53, 1413-1421.

13. Pereira, S. O.; Barros-Timmons, A.; Trindade, T., A Comparative Study of Chemical Routes for Coating Gold Nanoparticles via Controlled RAFT Emulsion Polymerization. Part. Part. Syst. Charact. 2017, 34, 1600202.

14. Cenacchi, A.; Pearson, S.; Kostadinova, D.; Leroux, F.; D'Agosto, F.; Lansalot, M.; Bourgeat-Lami, E.; Prevot, V., Nanocomposite latexes containing layered double hydroxides via RAFT-assisted encapsulating emulsion polymerization. Polym. Chem. 2017, 8, 12331243.

15. Zetterlund, P. B.; Thickett, S. C.; Perrier, S.; Bourgeat-Lami, E.; Lansalot, M., Controlled/Living Radical Polymerization in Dispersed Systems: An Update. Chem. Rev. 2015, $115,9745-9800$.

16. Bourgeat-Lami, E.; D’Agosto, F.; Lansalot, M., Synthesis of Nanocapsules and Polymer/Inorganic Nanoparticles Through Controlled Radical Polymerization At and Near Interfaces in Heterogeneous Media. Adv. Polym. Sci. 2016, 270, 123-161.

17. Mballa Mballa, M. A.; Ali, S. I.; Heuts, J. P.; van Herk, A. M., Control of the anisotropic morphology of latex nanocomposites containing single montmorillonite clay particles prepared by conventional and reversible addition-fragmentation chain transfer based emulsion polymerization. Polym. Int. 2012, 61, 861-865.

18. Bertolino, V.; Cavallaro, G.; Lazzara, G.; Milioto, S.; Parisi, F., Biopolymer-Targeted Adsorption onto Halloysite Nanotubes in Aqueous Media. Langmuir 2017, 33, 3317-3323. 
19. Cavallaro, G.; Lazzara, G.; Milioto, S., Exploiting the Colloidal Stability and Solubilization Ability of Clay Nanotubes/Ionic Surfactant Hybrid Nanomaterials. J. Phys. Chem. C 2012, $116,21932-21938$.

20. Cavallaro, G.; Lazzara, G.; Milioto, S.; Parisi, F., Hydrophobically Modified Halloysite Nanotubes as Reverse Micelles for Water-in-Oil Emulsion. Langmuir 2015, 31, 7472-7478.

21. Ruggerone, R.; Plummer, C. J. G.; Herrera, N. N.; Bourgeat-Lami, E.; Manson, J.-A. E., Highly filled polystyrene-laponite nanocomposites prepared by emulsion polymerization. Eur. Polym. J. 2009, 45, 621-629.

22. Theng, B. K. G., Some Practical Applications of the Clay-Polymer Interaction. In Formation and Properties of Clay-Polymer Complexes, 2nd ed.; Elsevier: 2012; pp 153-199.

23. Boursier, T.; Chaduc, I.; Rieger, J.; D'Agosto, F.; Lansalot, M.; Charleux, B., Controlled radical polymerization of styrene in miniemulsion mediated by PEO-based trithiocarbonate macromolecular RAFT agents. Polym. Chem. 2011, 2, 355-362.

24. Guimaraes, T. R.; Chaparro, T. d. C.; D'Agosto, F.; Lansalot, M.; dos Santos, A. M.; Bourgeat-Lami, E., Synthesis of multi-hollow clay-armored latexes by surfactant-free emulsion polymerization of styrene mediated by poly(ethylene oxide)-based macroRAFT/Laponite complexes. Polym. Chem. 2014, 5, 6611-6622.

25. Langmuir, I., The adsorption of gases on plane surfaces of glass, mica and platinium J. Am. Chem. Soc. 1918, 40, 1361-1403.

26. Adamson, A. W.; Gast, A. P., Physical chemistry of surfaces. Wiley: 1997.

27. Sips, R., On the structure of a catalyst surface $J$. Chem. Phys. 1948, 16, 490-495.

28. Redlich, O.; Peterson, D. L., A useful adsorption isotherm. J. Phys. Chem. 1959, 63, 10241024. 
29. Ebadi, A.; Mohammadzadeh, J. S. S.; Khudiev, A., What is the correct form of BET isotherm for modeling liquid phase adsorption? Adsorption 2009, 15, 65-73.

30. Tombacz, E.; Szekeres, M., Colloidal behavior of aqueous montmorillonite suspensions: the specific role of $\mathrm{pH}$ in the presence of indifferent electrolytes. Appl. Clay Sci. 2004, 27, 7594.

31. Rinaldi, D.; Hamaide, T.; Graillat, C.; D'Agosto, F.; Spitz, R.; Georges, S.; Mosquet, M.; Maitrasse, P., RAFT Copolymerization of Methacrylic Acid and Poly(ethylene glycol) Methyl Ether Methacrylate in the Presence of a Hydrophobic Chain Transfer Agent in Organic Solution and in Water. J. Polym. Sci. Part A: Polym. Chem. 2009, 47, 3045-3055.

32. Sahnoun, M.; Charreyre, M. T.; Veron, L.; Delair, T.; D'Agosto, F., Synthetic and characterization aspects of dimethylaminoethyl methacrylate reversible addition fragmentation chain transfer (RAFT) polymerization. J. Polym. Sci. Part A: Polym. Chem. 2005, 43, 3551-3565.

33. Luckham, P. F.; Rossi, S., The colloidal and rheological properties of bentonite suspensions. Adv. Colloid Interface Sci. 1999, 82, 43-92.

34. Pecini, E. M.; Avena, M. J., Measuring the Isoelectric Point of the Edges of Clay Mineral Particles: The Case of Montmorillonite. Langmuir 2013, 29, 14926-14934.

35. Lacik, I.; Stach, M.; Kasak, P.; Semak, V.; Uhelska, L.; Chovancova, A.; Reinhold, G.; Kilz, P.; Delaittre, G.; Charleux, B.; Chaduc, I.; D'Agosto, F.; Lansalot, M.; Gaborieau, M.; Castignolles, P.; Gilbert, R. G.; Szablan, Z.; Barner-Kowollik, C.; Hesse, P.; Buback, M., SEC Analysis of Poly(Acrylic Acid) and Poly(Methacrylic Acid). Macromol. Chem. Phys. 2015, 216, 23-37.

36. Giles, C. H.; Smith, D.; Huitson, A., General treatment and classification of solute adsorption isotherm. 1. Theoretical J. Colloid Interface Sci. 1974, 47, 755-765. 
37. Limousin, G.; Gaudet, J. P.; Charlet, L.; Szenknect, S.; Barthes, V.; Krimissa, M., Sorption isotherms: A review on physical bases, modeling and measurement. Appl. Geochem. 2007, $22,249-275$.

38. Naderi, A.; Iruthayaraj, J.; Pettersson, T.; Makuška, R.; Claesson, P. M., Effect of Polymer Architecture on the Adsorption Properties of a Nonionic Polymer. Langmuir 2008, 24, 66766682.

39. Shen, Y.-H., Estimation of surface area of montmorillonite by ethylene oxide chain adsorption. Chemosphere 2002, 48, 1075-1079.

40. Rossi, S.; Luckham, P. F.; Tadros, T. F., Influence of non-ionic polymers on the rheological behaviour of $\mathrm{Na}+-$-montmorillonite clay suspensions. Part II. Homopolymer ethyleneoxide and polypropylene oxide-polyethylene oxide ABA copolymers. Colloids Surf., A: Physicochem. Eng. Asp. 2003, 215, 1-10.

41. Ait-Akbour, R.; Boustingorry, P.; Leroux, F.; Leising, F.; Taviot-Guého, C., Adsorption of PolyCarboxylate Poly(ethylene glycol) (PCP) esters on Montmorillonite (Mmt): Effect of exchangeable cations $\left(\mathrm{Na}^{+}, \mathrm{Mg} 2+\right.$ and $\left.\mathrm{Ca} 2+\right)$ and PCP molecular structure. J. Colloid Interface Sci. 2015, 437, 227-234.

42. Souza, C. E. C.; Lima, A. S.; Nascimento, R. S. V., Hydrophobically modified poly(ethylene glycol) as reactive clays inhibitor additive in water-based drilling fluids. J. Appl. Polym. Sci. 2010, $117,857-864$.

43. Laguecir, A.; Ulrich, S.; Labille, J.; Fatin-Rouge, N.; Stoll, S.; Buffle, J., Size and pH effect on electrical and conformational behavior of poly(acrylic acid): Simulation and experiment. Eur. Polym. J. 2006, 42, 1135-1144.

44. Balazs, A. C.; Gempe, M.; Lantman, C. W., Effect of molecular architecture on the adsorption of copolymers Macromolecules 1991, 24, 168-176. 
45. Bassmann, F.; Sequaris, J. M.; Narres, H. D.; Schwuger, M. J., Adsorption of nonionic and anionic polymers on gamma-alumina and Na-montmorillonite and their mixtures. $J$. Dispersion Sci. Technol. 1999, 20, 607-620.

46. Zaman, A. A.; Tsuchiya, R.; Moudgil, B. M., Adsorption of a low-molecular-weight polyacrylic acid on silica, alumina, and kaolin. J. Colloid Interface Sci. 2002, 256, 73-78.

47. Marcelo, G.; Martinho, J. M. G.; Farinha, J. P. S., Polymer-Coated Nanoparticles by Adsorption of Hydrophobically Modified Poly(N,N-dimethylacrylamide). J. Phys. Chem. B 2013, 117, 3416-3427.

48. Chen, Y.; Xu, W.; Xiong, Y.; Peng, C.; Liu, W.; Zeng, G.; Peng, Y., Synthesis and characterization of $\mathrm{pH}$ and temperature double-sensitive nanocomposite hydrogels consisting of poly(dimethylaminoethyl methacrylate) and clay. J. Mater. Res. 2013, 28, 1394-1404.

49. Assem, Y.; Khalaf, A. I.; Rabia, A. M.; Yehia, A. A.; Zidan, T. A., Synthesis and characterization of hybrid clay/poly (N,N-dimethylaminoethyl methacrylate) nanocomposites. Polym. Compos. 2016, 37, 2950-2959.

50. Theng, B. K. G.; Theng, B. K. G., Positively Charged Polymers (Polycations). In Formation and Properties of Clay-Polymer Complexes, Elsevier: 2012; Vol. 4, pp 129-151.

51. Kotov, N. A.; Haraszti, T.; Turi, L.; Zavala, G.; Geer, R. E.; Dekany, I.; Fendler, J. H., Mechanism of and defect formation in the self-assembly of polymeric polycationmontmorillonite ultrathin films. J. Am. Chem. Soc. 1997, 119, 6821-6832.

52. Zadaka, D.; Radian, A.; Mishael, Y. G., Applying zeta potential measurements to characterize the adsorption on montmorillonite of organic cations as monomers, micelles, or polymers. J. Colloid Interface Sci. 2010, 352, 171-177. 
53. Kohay, H.; Izbitski, A.; Mishael, Y. G., Developing Polycation-Clay Sorbents for Efficient Filtration of Diclofenac: Effect of Dissolved Organic Matter and Comparison to Activated Carbon. Environ. Sci. Technol. 2015, 49, 9280-9288.

54. Radian, A.; Mishael, Y. G., Characterizing and designing polycation - Clay nanocomposites as a basis for imazapyr controlled release formulations. Environ. Sci. Technol. 2008, 42, 1511-1516.

55. Breen, C., The characterisation and use of polycation-exchanged bentonites. Appl. Clay Sci. 1999, $15,187-219$.

56. Churchman, G. J., Formation of complexes between bentonite and different cationic polyelectrolytes and their use as sorbents for non-ionic and anionic pollutants. Appl. Clay Sci. 2002, 21, 177-189.

57. Darder, M.; Colilla, M.; Ruiz-Hitzky, E., Chitosan-clay nanocomposites: application as electrochemical sensors. Appl. Clay Sci. 2005, 28, 199-208.

58. Pavlovic, M.; Adok-Sipiczki, M.; Nardin, C.; Pearson, S.; Bourgeat-Lami, E.; Prevot, V.; Szilagyi, I., Effect of MacroRAFT Copolymer Adsorption on the Colloidal Stability of Layered Double Hydroxide Nanoparticles. Langmuir 2015, 31, 12609-12617.

59. Ploehn, H. J.; Liu, C., Quantitative analysis of montmorillonite platelet size by atomic force microscopy. Ind. Eng. Chem. Res. 2006, 45, 7025-7034. 
TOC GRAPHIC

\section{Adsorption of MacroRAFT Agents onto MMT Clay}

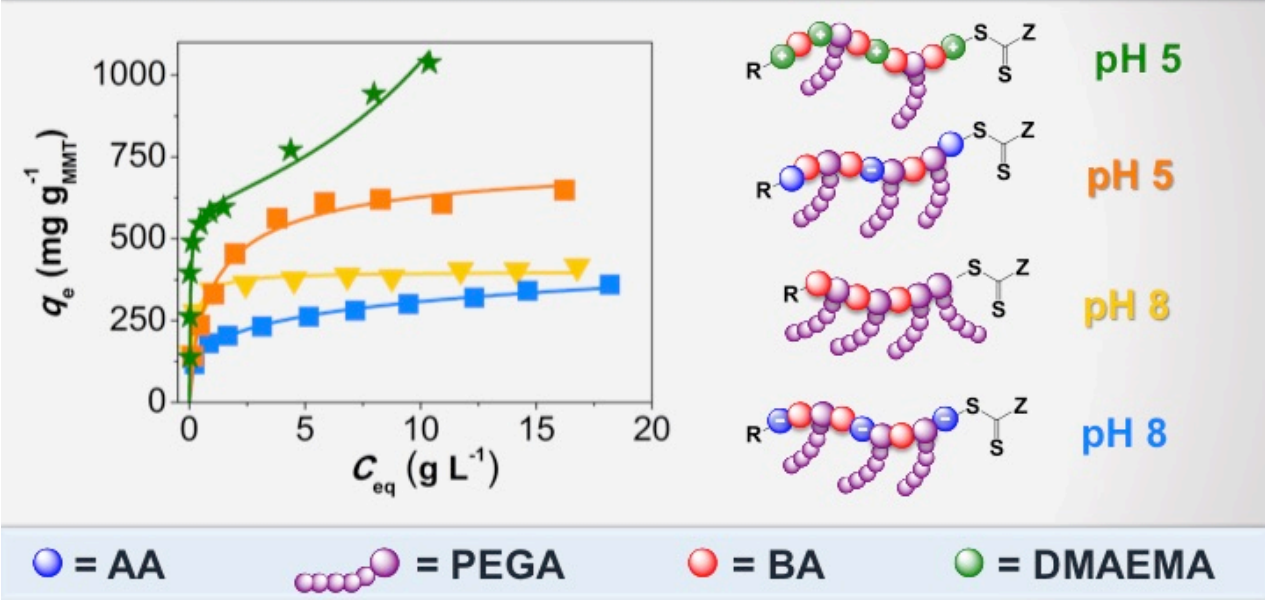

